\title{
UJI DAYA SIMPAN BENIH JENGKOL (Pithecellobium lobatum) DENGAN MENGGUNAKAN BEBERAPA MEDIA SIMPAN
}

\section{(STORABILITY TEST OF JENGKOL (Pithecellobim lobatum) SEED BY USING SOME STORAGE MEDIA)}

\author{
Fitri Lestari Manurung, Melya Riniarti, dan Duryat \\ Jurusan Kehutanan Fakultas Pertanian Universitas Lampung, \\ Jl. Soemantri Brojonegoro No. 1 Bandar Lampung \\ E-mail : lestari.fitri67@yahoo.com \\ No. Telepon : 082168127926
}

\begin{abstract}
ABSTRAK
Jengkol (Pithecellobium lobatum) merupakan salah satu tanaman MPTs yang berasal dari famili Fabaceae. Benih jengkol termasuk benih rekalsitran yaitu tidak tahan disimpan pada suhu dan kelembaban yang rendah. Penelitian ini bertujuan untuk mengetahui pengaruh lama penyimpanan dan media penyimpanan terhadap daya simpan benih jengkol, media penyimpanan yang efektif dalam memperpanjang daya simpan benih jengkol, dan interaksi antara lama waktu penyimpanan dan media simpan terhadap benih jengkol. Penelitian ini disusun secara faktorial ( 3 x 4) dalam Rancangan Acak Lengkap (RAL). Faktor I adalah lama penyimpanan $(\mathrm{T})$ yang terdiri dari $\mathrm{T}_{0}$ (tanpa penyimpanan), $\mathrm{T}_{1}$ (penyimpanan 2 minggu), $\mathrm{T}_{2}$ (penyimpanan 4 minggu), dan $\mathrm{T}_{3}$ (penyimpanan 6 minggu). Faktor II media penyimpanan (M) yang terdiri dari $\mathbf{M}_{0}$ (tanpa penyimpanan), $\mathbf{M}_{1}$ (media simpan serbuk gergaji), dan $\mathrm{M}_{2}$ (arang sekam padi). Setiap kombinasi perlakuan diulang sebayak 3 kali. Setiap unit percobaan yang digunakan terdiri dari 40 benih. Variabel yang diamati terdiri dari persentase benih berkecambah di penyimpanan, jumlah benih berkecambah, rata-rata hari berkecambah dan daya berkecambah. Homogenitas data diuji dengan uji Bartlett. Analisis varians digunakan untuk mengetahui apakah ada salah satu perlakuan berpengaruh nyata. Analisis lanjut dilakukan dengan uji beda nyata terkecil. Seluruh perhitungan data dilakukan pada taraf nyata 5\%. Hasil penelitian menunjukkan bahwa penyimpanan benih jengkol dengan menggunakan media simpan arang sekam padi dengan lama penyimpanan 6 minggu memberikan pengaruh terbaik untuk mempertahankan daya simpan benih. Media yang paling efektif dalam memperpanjang daya simpan benih jengkol adalah media arang sekam yang dapat mempertahankan viabilitas benih jengkol sampai dengan 6 minggu waktu penyimpanan.
\end{abstract}

Kata kunci : jengkol, lama penyimpanan, perkecambahan, media simpan

\section{ABSTRACT}

Jengkol (Pithecellobium lobatum) is one of MPTs that is included of Fabaceae Family. Jengkol seed is counted as recalcitrant, which is could not defend it is viability when it is stored at low temperature and humidity. The study aims were to determine the effect of storage time and storage media to storability of jengkol seed, storage media effective to maintain the jengkol seed viability, and the interaction between the storage media and the storage time to jengkol seed. The reseach design of factorial $(3 \times 4)$ in a completely randomized was employed as a research method. The first factor was the storage time $(T)$ which was consisted of $T_{0}$ (without storage), $T_{1}$ (2 weeks of storage), $T_{2}$ (4 weeks of storage), and $T_{3}$ (6 weeks of storage). Second factor was storage media $(M)$ which was consisted of $M_{0}$ (without storage media), $M_{1}$ (sawdust storage media), and $M_{2}$ (rice husk storage media). For 
each combination treatment was repeated 3 times. Each unit of experiments consisted of 40 seeds. The observed variables were germinated seeds in storage, the number of germinated seeds, avarage day to germination and germination power. Bartlett test was used to figure out the homogenity of datas. Varians analysis was at least one used to see if there was at least one significant treatment. The smalles significant differences test was used as further test. The entire data were tested on 5\% significant level. The results showed that storage of jengkol seed using rice husk for storage media with storage time of 6 weeks gave the best effect for maintaining the shelf life of the seeds. The most effective media to maintain the viability of jengkol seeds is rice husk which can defend the jengkol seeds viability up to 6 weeks of storage.

Keywords : jengkol, germination, storage media, storage time

\section{PENDAHULUAN}

Jengkol (Pithecellobium lobatum) merupakan salah satu tanaman MPTs yang berasal dari famili Fabaceae. Hampir seluruh bagian tanaman jengkol bermanfaat. Jengkol merupakan sumber makanan yang sangat digemari terutama masyarakat Indonesia. Kayu jengkol dapat dimanfaatkan untuk bahan baku kontruksi dan mebel, yaitu sebagai papan sambung interior, lemari, bahan pembuatan kapal, perabotan rumah tangga dan kayu bakar. Daunnya digunakan sebagai obat diabetes dan buahnya biasanya digunakan sebagai sayuran dan dijadikan keripik. Tanaman jengkol ini mampu hidup dengan baik pada daratan rendah sampai pada daerah pegunungan, yang tingginya $1.000 \mathrm{~m}$ dpl dan dapat hidup di beberapa tipe tanah, salah satunya tanah latosol. Di samping itu, tanaman jengkol juga tahan terhadap kekeringan (Pitojo, 1992).

Tanaman jengkol memiliki kegunaan yang beragam sehingga banyak di-manfaatkan masyarakat untuk memenuhi keperluan sehari-hari. Namun peman-faatan yang berlebihan tanpa adanya upaya regenerasi dikhawatirkan menye-babkan terjadinya kelangkaan tanaman jengkol tersebut. Oleh karena itu, dibutuh-kan suatu upaya untuk menjaga keberadaan populasi jengkol yaitu dengan cara pembudidayaan atau perbanyakan tanaman jengkol.

Benih jengkol termasuk ke dalam benih rekalsitran yaitu benih yang cepat rusak (viabilitas menurun) apabila diturunkan kadar airnya dan tidak tahan disimpan pada suhu dan kelembaban yang rendah. Oleh karena itu diperlukan suatu teknik/cara untuk menyimpan serta waktu dan media penyimpanan benih jengkol sehingga viabilitasnya tetap terjaga. Menurut Hasanah (2002), hal ini dapat dilakukan dengan cara memperhatikan media simpan yang tepat dalam mempertahankan viabilitas benih.

Beberapa upaya yang dapat dilakukan untuk meningkatkan daya simpan pada benih rekalsitran yaitu dengan memperhatikan media tersebut. Beberapa media yang umumnya digunakan untuk mempertahankan viabilitas benih antara lain, arang sekam padi dan serbuk gergaji. Arang sekam padi diketahui bersifat tidak beracun, berpengaruh dalam mempertahankan viabilitas benih, serta dapat mematikan hama pengganggu benih. Media penyimpanan berupa serbuk gergaji juga dapat mempertahankan viabilitas benih karena bersifat lambat lapuk sehingga media ini sangat baik untuk penyimpanan air dan dapat mempertahankan kelembaban di sekitar benih (Nurhayati, 2015).

Dalam penyimpanan benih jengkol selain waktu penyimpanan media simpan diperlukan juga untuk mempertahankan viabilitas benihnya. Robi'in (2007), mengatakan bahwa penyimpanan benih pada ruangan terbuka akan cepat me-ngalami kemunduran atau daya simpan menjadi singkat akibat adanya perubahan suhu dan kelembapan. Penggunaan media penyimpanan, baik arang sekam padi maupun serbuk gergaji dan suhu ruang simpan 
diharapkan mampu mempertahan-kan viabilitas benih jengkol dengan waktu yang lebih panjang.

Tujuan penelitian ini adalah mengetahui pengaruh lama penyimpanan dan media penyimpanan terhadap viabilitas masa simpan benih jengkol, mengetahui media penyimpanan yang paling efektif dalam memperpanjang viabilitas masa simpan benih jengkol dan mengetahui interaksi antara lama waktu penyimpanan dan media simpan terhadap benih jengkol.

\section{METODE PENELITIAN}

\section{Lokasi dan Waktu Penelitian}

Penelitian ini telah dilaksanakan di Laboratorium Silvikultur, Jurusan Kehutanan dan rumah kaca Fakultas Pertanian Universitas Lampung. Waktu penelitian dilaksanakan pada bulan Maret sampai dengan Juni 2015.

\section{Bahan dan Alat Penelitian}

Bahan yang digunakan yaitu benih jengkol, serbuk gergaji, arang sekam padi, kantong plastik transparan ukuran $70 \mathrm{~cm} \times 60 \mathrm{~cm}$ dan pasir. Alat yang digunakan adalah bak kecambah, cetok dan timbangan dengan ketelitian 0,0001 gram, higrometer dan gembor.

\section{Metode Penelitian}

\section{Rancangan Percobaan}

Penelitian ini disusun secara Faktorial (4 x 3) dalam Rancangan Acak Lengkap (RAL). Faktor I yaitu lama penyimpanan $(\mathrm{T})$ yang terdiri dari $\mathrm{T}_{0}$ yaitu tanpa penyimpanan, $\mathrm{T}_{1}$ yaitu lama penyimpanan 2 minggu, $\mathrm{T}_{2}$ yaitu lama penyimpanan 4 minggu, $\mathrm{T}_{3}$ yaitu lama penyimpanan 6 minggu. Faktor II media penyimpanan (M) yang terdiri dari $\mathrm{M}_{0}$ yaitu tanpa media simpan, $\mathbf{M}_{1}$ yaitu media simpan serbuk gergaji, $\mathbf{M}_{2}$ yaitu menggunakan media simpan arang sekam padi. Dengan demikian diperoleh 12 kombinasi perlakuan dan setiap kombinasi perlakuan diulang sebanyak $3 \mathrm{kali}$, sehingga satuan percobaan yang digunakan sebanyak 4 × 3 × $3=36$ unit/kantong, setiap kantong terdapat 40 benih.

\section{Kegiatan Penelitian}

\section{Persiapan Benih}

Pelaksanaan penelitian ini dilaksanakan dengan kegiatan sebagai berikut. Sumber benih diperoleh dari pohon jengkol yang berada di Laboratorium Lapangan Terpadu Fakultas Pertanian Universitas Lampung. Pengunduhan buah dilakukan pada buah yang telah masak secara fisiologis yaitu warna kulit berwarna coklat kehitaman, biji jengkol mempunyai kulit kuning kecoklatan sewaktu dikupas dari polongnya sudah terasa keras. Biji dikumpulkan dan dikemas dalam karung plastik, lalu biji dipisahkan dari kulitnya dengan cara mekanis yaitu mengkupas kulit dengan pisau dan itu dilakukan seleksi benih yang sehat.

\section{Penyiapan Media Simpan}

Media simpan yang digunakan dalam penelitian ini adalah serbuk gergaji dan arang sekam padi. Serbuk gergaji diperoleh dari panglong kayu, sedangkan arang sekam padi diperoleh dari pabrik pembakaran sekam padi. Kedua media simpan yang telah dikumpulkan tersebut kemudian dijemur di bawah sinar matahari untuk mensterilisasi media dari hama dan jamur, dan penyakit agar media simpan tidak terlalu basah. Sebelum digunakan, kadar air pada kedua media simpan tersebut diukur untuk mengetahui kelembaban pada media sebelum digunakan untuk menyimpan benih jengkol. Diusahakan agar kadar air 
pada media simpan sama dengan kadar air pada benih jengkol. Wadah yang digunakan untuk menyimpan benih jengkol adalah plastik transparan.

\section{Penempatan Benih dalam Media Simpan}

Benih yang telah diseleksi dikeringanginkan selama 2 jam, agar benih tidak terserang jamur. Kemudian dimasukkan dalam kantong plastik transparan $70 \mathrm{~cm}$ x $60 \mathrm{~cm}$, setiap kantong plastik diisi dengan media simpan sebanyak $500 \mathrm{~g}$ dan 40 benih. Benih jengkol dibenamkan ke dalam media simpan sampai menutupi benih jengkol.

\section{Penyimpanan Benih Jengkol}

Benih jengkol yang sudah diberi perlakuan dengan menggunakan media simpan serbuk gergaji dan arang sekam padi setiap kemasan yang berbeda-beda. Benih yang telah dibenamkan dalam media simpan kemudian disimpan di ruangan penyimpanan Laboraturium Silvikultur dengan suhu kamar $25^{\circ} \mathrm{C}$. Setiap perlakuan yang diberi media simpan serbuk gergaji dan arang sekam padi disimpan dengan waktu yang berbeda-beda yaitu dengan lama simpan 2 minggu, 4 minggu dan 6 minggu penyimpanan.

\section{Pengujian Daya Perkecambahan}

\section{a. Persiapan Media Kecambah Benih}

Benih jengkol dikecambahkan pada bak kecambah $30 \mathrm{~cm}$ x $25 \mathrm{~cm}$ x $10 \mathrm{~cm}$. Media perkecambahan yang digunakan berupa pasir. Pasir yang digunakan untuk media perkecambahan telah melalui pengayakan yang bertujuan untuk mendapatkan tekstur media yang halus dan dilakukan sterilisasi media yaitu dengan menyangrai media selama 20 menit, bertujuan untuk membasmi hama dan jamur yang dapat merusak benih. Media pasir digunakan sebagai media kecambah benih jengkol.

\section{b. Perkecambahan}

Benih jengkol yang telah diberi perlakuan, dilakukan penyimpanan menggunakan media simpan sesuai rancangan perlakuan. kemudian dikecambahkan dengan cara membenamkan benih pada media kecambah dengan kedalaman $5 \mathrm{~cm}$. Pengamatan dilakukan setiap hari, dan menghitung jumlah benih yang berkecambah setiap hari.

\section{c. Pemeliharaan Media Kecambah.}

Pemeliharaan yang dilakukan setiap hari yaitu dengan cara membersihkan gulma yang tumbuh di dalam bak kecambah serta menyiram tanaman pada pagi hari.

\section{a. Variabel Pengamatan}

Parameter pengamatan dalam penelitian yaitu jumlah benih berakar di penyimpanan, jumlah benih berkecambah, rata-rata hari berkecambah dan daya kecambah. (Indriyanto, 2011).

1. Persentase benih jengkol yang berakar selama penyimpanan benih dihitung apabila benih berkecambah pada saat disimpan dihitung dengan rumus

$$
\text { Benih berkecambah }=\frac{\text { jumlah benih jengkol berakar }}{\text { jumlah benih jengkol yang disimpan }} \times 100 \%
$$

2. Persentase jumlah benih yang berkecambah $(\mathrm{G})$

$$
\mathrm{G}=\frac{j u m l a h \text { benih yang berkecambah }}{\text { jumlah benih yang dikecambahkan }} \times 100 \%
$$


3. Rata-rata Hari Berkecambah (GR)

$$
\begin{aligned}
\mathrm{GR} & =\frac{n 1 \times h 1+n 2 \times h 2+\cdots+(n k \times h k)}{n 1+n 2+\cdots+n k} \\
\mathrm{n} & =\text { jumlah benih berkecambah } \\
\mathrm{h} & =\text { hari dalam proses perkecambahan }
\end{aligned}
$$

4. Daya kecambah (DK)

$$
\mathrm{DK}=\frac{\sum \text { benih bekecambah }+\sum \text { benih yang tidak berkecambah (berpotensi) }}{\sum \text { benih yang dikecambahkan }} \times 100 \%
$$

\section{Analisis Data}

\section{a. Homogenitas Ragam}

Untuk mengetahui homogenitas ragam, dilakukan Uji Bartlett dengan taraf 5\% (Gaspersz,1991).

\section{b. Analisis Ragam}

Untuk menguji hipotesis ada atau tidaknya faktor perlakuan terhadap parameter yang diamati, dilakukan analisis sidik ragam (uji F) dengan taraf nyata 5\% .

\section{c. Uji Beda Nyata Terkecil}

Untuk menunjukkan perbedaan masing-masing perlakuan atau beda nyata antar perlakuan, dilakukan uji Beda Nyata Terkecil (BNT) dengan taraf nyata 5\% (Hanafiah, 2011).

\section{HASIL DAN PEMBAHASAN}

\section{Hasil}

Seluruh variabel penelitian diuji dengan uji Bartlett untuk mengetahui homo- genitas ragam. Berdasarkan hasil uji Bartlett, diketahui bahwa keseluruhan variabel pengamatan sudah homogen. Oleh karena itu dilakukan analisis sidik ragam apakah ada paling tidak satu perlakuan yang berpengaruh. Hasil rekapitulasi analisis sidik ragam setiap variabel penelitian

\begin{tabular}{|c|c|c|c|c|c|}
\hline \multirow[b]{2}{*}{ Perlakuan } & \multicolumn{4}{|c|}{$\mathbf{F}_{\text {hitung }}$ pada setiap variabel penelitian } & \multirow[b]{2}{*}{$\begin{array}{l}\mathrm{F} \text { tabel } \\
5 \%\end{array}$} \\
\hline & $\begin{array}{l}\text { Benih yang ber } \\
\text { akar di } \\
\text { penyimpanan }\end{array}$ & $\begin{array}{l}\text { jumlah benih } \\
\text { berkecambah }\end{array}$ & $\begin{array}{l}\text { Rata-rata hari } \\
\text { berkecambah }\end{array}$ & $\begin{array}{c}\text { Daya } \\
\text { berkecambah }\end{array}$ & \\
\hline $\begin{array}{c}\text { lama } \\
\text { penyimpanan } \\
\text { (T) }\end{array}$ & $150,63 *$ & $25,43^{*}$ & $33,45^{*}$ & $38,30 *$ & 3,01 \\
\hline $\begin{array}{l}\text { media simpan } \\
\text { (M) }\end{array}$ & $1345,27 *$ & $28,43^{*}$ & $41,61 *$ & $50,09 *$ & 3,40 \\
\hline $\mathrm{T} \times \mathrm{M}$ & $150,63^{*}$ & $11,12^{*}$ & $10,14^{*}$ & $19,32 *$ & 2,51 \\
\hline
\end{tabular}
uji daya simpan benih jengkol disajikan pada Tabel 1 .

Tabel 1. Rekapitulasi hasil analisis sidik ragam uji daya simpan benih jengkol dengan menggunakan beberapa media simpan dan lama waktu penyimanan.

Hasil analisis sidik ragam menunjukkan bahwa paling tidak terdapat satu per-lakuan lama penyimpanan yang berpengaruh terhadap benih yang berakar dipe-nyimpanan, jumlah benih berkecambah, rata-rata hari berkecambah dan daya berkecambah. Hasil analisis ragam 
juga menunjukkan bahwa paling tidak ter-dapat satu perlakuan media simpan yang berpengaruh terhadap benih yang berakar di penyimpanan, jumlah benih berkecambah, ratarata hari berkecambah dan daya kecambah dan terdapat paling tidak satu perlakuan interaksi yang ber-pengaruh nyata terhadap jumlah benih berakar di penyimpanan, jumlah benih berkecambah, rata-rata hari berkecambah dan daya berkecambah. Untuk melihat perbedaan pada setiap taraf perlakuan dilakukan uji lanjut dengan uji Beda Nyata Terkecil (BNT). Rekapitulasi hasil uji BNT pada jumlah benih berakar di penyimpanan, jumlah benih berkecambah, rata-rata hari berkecambah dan daya berkecambah disajikan pada Tabel 2, 3, dan 4.

Tabel 2. Persentase jumlah benih berkecambah pada saat dikecambahkan dengan perlakuan media simpan dan lama penyimpanan $(\%)$.

\begin{tabular}{cccc}
\hline $\begin{array}{c}\text { Perlakuan lama } \\
\text { penyimpanan }\end{array}$ & Tanpa media & Serbuk gergaji & Arang sekam padi \\
\hline 0 minggu & $75,17 \mathrm{ab}$ & $75,17 \mathrm{ab}$ & $75,17 \mathrm{ab}$ \\
2 minggu & $70,83 \mathrm{ab}$ & $5,00 \mathrm{~cd}$ & $44,84 \mathrm{~b}$ \\
4 minggu & $0,00 \mathrm{~d}$ & $0,00 \mathrm{~d}$ & $83,63 \mathrm{a}$ \\
6 minggu & $0,00 \mathrm{~d}$ & $0,00 \mathrm{~d}$ & $55,85 \mathrm{bc}$ \\
\hline
\end{tabular}

Keterangan : $\mathrm{BNT}_{0,05}=24,83$

Data pada setiap kolom yang diikuti oleh huruf yang sama tidak berbeda nyata pada taraf $5 \%$.

Hasil uji BNT menunjukkan bahwa benih yang disimpan tanpa media penyim-panan akan kehilangan kemampuan berkecambahnya setelah 2 minggu. Penyim-panan dengan media arang sekam padi mampu mempertahankan kecepatan berkecambah benih sampai dengan lama penyimpanan 6 minggu. Benih yang disimpan dalam media serbuk gergaji akan langsung kehilangan kemampuan berkecambah setelah penyimpanan 2 minggu.

Tabel 3. Rata-rata hari berkecambah benih diperkecambahan dengan perlakuan media penyimpanan dan lama penyimpanan (\% hari).

\begin{tabular}{cccc}
\hline $\begin{array}{c}\text { Perlakuan lama } \\
\text { penyimpanan }\end{array}$ & Tanpa media & Serbuk gergaji & Arang sekam padi \\
\hline 0 minggu & $35,41 \mathrm{ab}$ & $35,41 \mathrm{ab}$ & $35,41 \mathrm{ab}$ \\
2 minggu & $34,86 \mathrm{ab}$ & $12,27 \mathrm{~cd}$ & $33,52 \mathrm{ab}$ \\
4 minggu & $0,00 \mathrm{e}$ & $0,00 \mathrm{e}$ & $34,84 \mathrm{ab}$ \\
6 minggu & $0,00 \mathrm{e}$ & $0,00 \mathrm{e}$ & $32,95 \mathrm{~b}$ \\
\hline
\end{tabular}

Keterangan: $\mathrm{BNT}_{0,05}=10,47$

Data pada setiap kolom yang diikuti oleh huruf yang sama tidak berbeda nyata pada taraf $5 \%$.

Hasil uji BNT menunjukkan bahwa penyimpanan benih tanpa media simpan selama 2 minggu berpengaruh terhadap rata-rata hari berkecambah. Penyim-panan benih dalam media serbuk gergaji selama 2 minggu mampu mempercepat rata-rata hari berkecambah benih jengkol 23 hari penyimpanan benih benih jengkol dalam media arang sekam padi terdapat pengaruh terhadap kecepatan berkecambah jengkol. 
Tabel 4. Daya kecambah benih diperkecambahan dengan perlakuan media simpan dan lama penyimpanan $(\%)$.

\begin{tabular}{cccc}
\hline $\begin{array}{c}\text { Perlakuan lama } \\
\text { penyimpanan }\end{array}$ & Tanpa media & Serbuk gergaji & Arang sekam padi \\
\hline 0 minggu & $91,67 \mathrm{~b}$ & $91,67 \mathrm{a}$ & $91,67 \mathrm{a}$ \\
2 minggu & $99,17 \mathrm{a}$ & $5,00 \mathrm{de}$ & $62,51 \mathrm{c}$ \\
4 minggu & $0,00 \mathrm{f}$ & $0,00 \mathrm{f}$ & $93,72 \mathrm{a}$ \\
6 minggu & $0,00 \mathrm{f}$ & $0,00 \mathrm{f}$ & $81,82 \mathrm{~b}$ \\
\hline
\end{tabular}

Keterangan: $\mathrm{BNT}_{0,05}=24,17$

Data pada setiap kolom yang diikuti oleh huruf yang sama tidak berbeda nyata pada taraf $5 \%$

Benih yang disimpan selama 2 minggu tanapa media simpan ternyata daya kecambahnya justru lebih baik dibandingkan dengan kontrol. Penyimpanan benih dengan media serbuk gergaji selama 2 minggu secara drastis menurunkan daya kecambah benih. Benih yang disimpan dalam media arang sekam padi selama 4 minggu akan memiliki daya kecambah sama baiknya dengan kontrol. Tetapi benih yang disimpan selama 4 minggu berbeda nyata dengan penyimpanan 2 minggu. Pada benih yang disimpan selama 4 dan 6 minggu berbeda nyata dengan penyimpanan 2 minggu.

\section{Pembahasan}

Salah satu upaya untuk meningkatkan keberhasilan, mempertahankan vibilitas benih rekalsitran di penyimpanan yaitu dengan cara penyimpanan benih menggu-nakan media simpan seperti serbuk gergaji dan arang sekam padi. Benih jengkol termasuk benih rekelsitran yaitu benih yang tidak tahan dikeringkan peka terhadap suhu dan kelembaban rendah (Daniel, 2009).

Media simpan yang ternyata mampu mempertahankan, benih jengkol untuk tidak berkecambah selama penyimpanan 2, 4 dan 6 minggu adalah media simpan serbuk gergaji dan tanpa media simpan. Sedangkan untuk media simpan yang berupa media arang sekam padi selama penyimpanan 2, 4 dan 6 tidak mampu mempertahankan benih untuk tidak berkecambah selama penyimpanan.

Benih yang di simpan dengan media serbuk gergaji tidak dapat mempertahankan viabiliatas benih pada saat di simpan diduga suhu ruangan terlalu tinggi dan kemasan yang digunakan kedap udara sehingga mengakibatkan benih yang disimpan mengalami busuk dan berjamur. Menurut Oktralixon dkk (2015), suhu udara yang terlalu tinggi pada saat penyimpanan mengakibatkan kerusakan pada benih karena akan memperbesar terjadinya penguapan zat cair dari dalam benih, sehingga benih akan kehilangan imbibisi dan kemampuan untuk berkecambah.

Menurut Yuniarti dkk (2015), benih rekalsitran tidak dikemas dalam plastik yang kedap udara yaitu untuk mencegah pengeringan menekan kematian mikroba dan dapat memelihara oksingen. Wadah yang tepat untuk penyimpanan yaitu karung goni, kain blancu yang tidak kedap agar pertukaran udara tetap terjadi sehingga terhindar dari panas yang berlebih.

Sedangkan pada penyimpanan benih dengan menggunakan arang sekam padi benih berkecambah di penyimpanan, tetapi ketika dikecambahkan benih tersebut mampu tumbuh dengan baik pada saat dikecambahkan. Hal ini diduga karena benih yang disimpan mengalami peningkatan kadar air selama penyimpanan sehingga benih berkecambah pada saat disimpan. Hal ini berbeda dengan peneli-tian yang dilakukan Pratiwi dkk (2010), pemberian arang sekam padi semakin banyak pada benih lengkeng yang disimpan selama dua 
minggu menyebabkan persentase kemunculan bibit semakin rendah dan semakin lama benih lengkeng disimpan semakin rendah persentase kemunculan bibit dibedengan.

Menurut Hayati dkk (2011), pertumbuhan awal benih rekalsitran merupakan masalah utama dalam proses penyimpanannya. Benih-benih rekalsitran seperti benih kakao tidak memiliki masa dormansi dan akan segera tumbuh meskipun disimpan. Menurut Baharudin dkk (2010), bahwa benih rekalsitaran mempunyai masa hidup yang sangat singkat dan sukar untuk disimpan dikarenakan kadar air yang tinggi menyebabkan benih mudah terkontaminasi mikroba dan lebih cepat mengalami kemunduran.

\section{KESIMPULAN}

Dari hasil penelitian, dapat disimpulkan sebagai berikut.

1. Tanpa media simpan, viabilitas benih jengkol dapat bertahan hingga 2 minggu.

2. Penggunaan serbuk gergaji tidak mampu mempertahankan viabilitas benih jengkol.

3. Arang sekam adalah media simpan yang terbaik untuk benih jengkol karena mampu mempertahankan viabilitas benih jengkol selama 6 minggu.

\section{DAFTAR PUSTAKA}

Baharudin, I. Satriyas, R. Mohamad dan P. Agus. 2010. Pengaruh pengaruh lama penyimpanan dan perlakuan benih terhadap peningkatan kako hibridanal. Jurnal Pengkajian dan Pengembangan Teknologi Pertanian. 1(13):73-84.

Daniel, E. M. 2009. Vigor benih kakao (Theobroma cacao l.) pada berbagai lama penyimpanan dan invigorasi. Jurnal Agroland. 16(3)206-212.

Gaspersz, V. 1991. Metode Perancangan Percobaan. Buku. Armico. Bandung. 472 p.

Hanafiah, K. A. 2011. Rancangan Percobaan Teori dan Aplikasi. Buku. PT. Raja Grafindo Persada. Jakarta. $259 \mathrm{p}$

Hayati, R . J. Abidin, Pian dan S. AS. 2011. Pengaruh tingkat kemasan buah dan cara penyimpanan terhadap vigor dan viabilitas benih kakao ( Theobroma cacao L.). Jurnal Floratek 6(2):114-123.

Hasanah, M. 2002. Peranan mutu fisiologis benih dan pengembangan industri benih tanaman industri. Jurnal Penelitian dan Pengembangan Pertanian. 22(1):84-90.

Indriyanto, 2011. Panduan Praktikum Teknik dan Manajemen Bibit/Persemaian. Buku. Fakultas Pertanian Universitas Lampung. Bandar Lampung. 70 p.

Nurhayati, 2015. Pengaruh lama dan media penyimpanan benih terhadap perkecambahan karet (Havea brasiliensis Muell Arg) klon PB 260. Jurnal Produksi Tanaman. 3(7):607-614.

Oktaralixon, L. Yohanes, T. dan Andrianton. 2015. Peranan kemasan dan media simpan terhadap ketahanan viabilitas dan vigor benih nangka (Artocarpus heterophyllus). Jurnal Agrotekbis. 3 (3): 303-315.

Pratiwi, R. Rabaniyah, R dan Purwantoro, A. 2010. pengaruh jenis dan kadar air media simpan terhadap viabilitas benih lengkeng (dimocarpus longan lour). Jurnal Perbenihan Tanaman Hutan.2(6): 50-60.

Pitojo, S. 1992. Budidaya dan Manfaat Jengkol. Buku. Kanisius. Yogyakarta. 72p.

Rahardjo, P. 2012. Pengaruh pemberian arang sekam padi sebagai penyimpanan benih terhadap daya tumbuh dan pertumbuhan bibit kakao. Jurnal Pelita Perkebunan. 28(2):93-102.

Robi'in. 2007. Perbedaan bahan kemasan dan periode simpan dan pengaruhnya terhadap kadar air benih jagung dalam ruang simpan terbuka. Buletin Teknik Pertanian. $8(1): 7-8$. 
Syamsuwida.D., dan C. Kusmana. 2011. Pengaruh media simpan, ruang simpan, dan lama penyimpanan terhadap viabilitas benih Rhizophora stylosa Griff. Jurnal Silvikultur Tropika. 3(1):82-87.

Sastrosupadi. 2000. Rancangan Percobaan Praktis Bidang Pertanian. Buku. Kanisius. Malang. $276 \mathrm{p}$.

Sumampow, F. M. D. 2011. Viabilitas benih kakao (Theobroma cacao) pada media simpan serbuk gergaji. Jurnal Lingkungan Tanah. 3(2):70-72.

Yuniarti, N. dan Djaman, D. 2015. Teknik pengemasan yang tepat untuk mempertahankan viabilitas benih bakau (Rhizophora apiculata) selama penyimpanan. Jurnal Pro Sem Nas Masy Biodiv Indon. 1(6):139-144. 
Vol. 4 No. 2, April 2016 (69-78)

Halaman ini sengaja dikosongkan 